\title{
Organisational innovation, information technology, and outsourcing to business services
}

Citation for published version (APA):

Hoelzl, W., Reinstaller, A., \& Windrum, P. (2005). Organisational innovation, information technology, and outsourcing to business services. MERIT, Maastricht Economic Research Institute on Innovation and Technology. MERIT-Infonomics Research Memorandum Series No. 030 https://doi.org/10.26481/umamer.2005030

Document status and date:

Published: 01/01/2005

DOI:

10.26481/umamer.2005030

Document Version:

Publisher's PDF, also known as Version of record

\section{Please check the document version of this publication:}

- A submitted manuscript is the version of the article upon submission and before peer-review. There can be important differences between the submitted version and the official published version of record.

People interested in the research are advised to contact the author for the final version of the publication, or visit the DOI to the publisher's website.

- The final author version and the galley proof are versions of the publication after peer review.

- The final published version features the final layout of the paper including the volume, issue and page numbers.

Link to publication

\footnotetext{
General rights rights.

- You may freely distribute the URL identifying the publication in the public portal. please follow below link for the End User Agreement:

www.umlib.nl/taverne-license

Take down policy

If you believe that this document breaches copyright please contact us at:

repository@maastrichtuniversity.nl

providing details and we will investigate your claim.
}

Copyright and moral rights for the publications made accessible in the public portal are retained by the authors and/or other copyright owners and it is a condition of accessing publications that users recognise and abide by the legal requirements associated with these

- Users may download and print one copy of any publication from the public portal for the purpose of private study or research.

- You may not further distribute the material or use it for any profit-making activity or commercial gain

If the publication is distributed under the terms of Article $25 \mathrm{fa}$ of the Dutch Copyright Act, indicated by the "Taverne" license above, 


\section{MERIT-Infonomics Research Memorandum series}

Organisational innovation, information technology, and outsourcing to business services

Werner Hölzl, Andreas Reinstaller \& Paul Windrum

$2005-030$

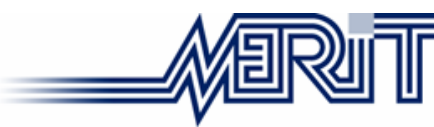

MERIT - Maastricht Economic Research Institute on Innovation and Technology

PO Box 616

6200 MD Maastricht

The Netherlands

T: +31433883875

F: +31 433884905

http://www.merit.unimaas.nl

e-mail:secr-merit@merit.unimaas.nl

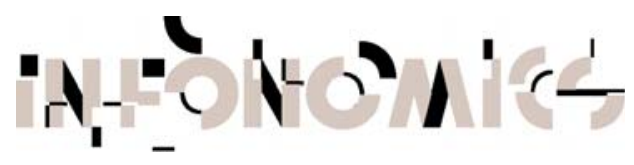

International Institute of Infonomics

c/o Maastricht University

PO Box 616

6200 MD Maastricht

The Netherlands

$\mathrm{T}:+31433883875$

F: +31 453884905

http://www.infonomics.nl

e-mail: secr@infonomics.nl 


\title{
Organisational innovation, information technology, and outsourcing to business services
}

\author{
Werner Hölzl, Andreas Reinstaller and \\ Paul Windrum ${ }^{1,2(++)}$
}

\begin{abstract}
This paper examines the relationship between organisational innovation, the introduction of new internet-based ICTs, de-verticalisation, and the rapid growth in business service outsourcing over the last decade. In order to examine this issue, we develop a model of organisational innovation. In this model, the goal of managers is to identify an organisational design that more effectively integrates all the administrative activities of the firm. As part of the process of innovation, the managers can choose to carry out an administrative activity in-house, or to outsource that activity. A key factor influencing this decision are the relative information costs of organising activities internally and the information costs associated with setting up and maintaining interfaces with external suppliers. The framework has been implemented in a novel model of organisational innovation. Simulations conducted on this model enabled us to consider the short- and long-run impacts of outsourcing on administration overheads and on long-term productivity growth. The interesting finding is that managers of a firm can become locked into a low productivity growth trajectory, associated with the outsourcing of activities, if they are myopic and learn through their own actions. They perceive outsourcing to cut overhead costs in the short-run (as expected), and so engage in further outsourcing thereafter. This is to the detriment of long-run productivity gains (system economies) generated though organisational innovation. This occurs because the potential for organisational innovation is reduced when modular components are outsourced, placing them beyond the control of the firms' management. The findings accord well with the empirical data, and provide a salutary warning for managers and policy-makers about the potential long-term implications of outsourcing
\end{abstract}

forthcoming in: L. Rubalcaba and H. Kox (eds), Business services in European economic growth, London: Palgrave MacMillan 2006/2007.

Keywords: Outsourcing, organisational innovation, long run productivity development JEL Codes: D23, D24, D83, O33

\footnotetext{
1 Addresses:

Werner Hölzl, Österreichisches Institut für Wirtschaftsforschung (WIFO), Postfach 91, A-1103 Vienna, Austria, e-mail: Werner.Hoelzl@wifo.ac.at

Andreas Reinstaller Vienna University of Economics and Business Administration, Department of Economics, Augasse 2-6, 1090 Vienna, Austria. MERIT, University of Maastricht, PO Box 616, 6200 MD Maastricht, The Netherlands. e-mail: Andreas.Reinstaller@wu-wien.ac.at

${ }^{(++)}$corresponding author, Paul Windrum, Manchester Metropolitan University Business School, Aytoun Building, Aytoun Street, Manchester M1 3GH, United Kingdom. MERIT, University of Maastricht, PO Box 616,6200 MD Maastricht, The Netherlands. e-mail: p.windrum@mmu.ac.uk

${ }^{2}$ The authors gratefully acknowledge supportive funding through the PUBLIN Project, European Commission's Framework 5 Programme.
} 


\section{Introduction}

This chapter examines the relationship between organisational innovation, the introduction of new internet-based ICTs, de-verticalisation, and the rapid growth in business service outsourcing over the last decade. We present data on the range of activities that are being outsourced, and discuss a set of potential advantages associated with outsourcing activities to knowledge-intensive service providers (KIBS). We also examine the latest empirical studies which throw up a set of potential disadvantages associated with outsourcing. These suggest that outsourcing may have advantages in the short-run but have negative long-run implications for competitive performance.

In order to examine this issue, we develop a model of organisational innovation. In this model, the goal of managers is to identify an organisational design that more effectively integrates all the administrative activities of the firm. As part of the process of innovation, the managers can choose to carry out an administrative activity in-house, or to outsource that activity. A key factor influencing this decision are the relative information costs of organising activities internally, and the information costs associated with setting up and maintaining interfaces with external suppliers. Herein lies the importance of new ICT. The introduction of new ICTs can alter the relative costs on internal and external administration. This captures a key stylised fact about knowledge-intensive business services (KIBS), such as business consultants, financial services, and ICT services: the rapid expansion of KIBS over the last decade is strongly connected the introduction and diffusion of internet-based networking ICTs.

The chapter is organised as follows. Section 2 introduces the key concepts of organisational design and organisational innovation. It then outlines the core theoretical approach that is used to conceptualise organisational innovation. This is based on a modular theory of the firm, which is founded on the twin principles of increasing specialisation and the modularisation of complex organisational structures. Increasing the modularity of the organisational structure not only leads to improvements in efficiency through specialisation, but enables a firm to realise systems economies, thereby pushing ahead the productivity frontier. At the core of the theoretical framework is a transmission mechanism between ICT adoption, organisational innovation and outsourcing. This transmission mechanism enables one to analyse the conditions under the adoption of new ICTs leads to organisational innovation, de-verticalisation, and outsourcing. Using this theoretical framework we are able to critically discuss the long-run implications of outsourcing on productivity.

Section 3 reviews recent empirical studies in order to identify a set of potential benefits and potential disadvantages associated with the outsourcing of activities to business services. The most recent empirical literature highlights differences in short and long-run benefits and costs. In the short-run, outsourcing firms are able to reduce costs because the number of personnel are reduced (i.e. the wage bill is cut) and savings are made because these activities no longer need to be administered internally. However, there are long-term costs. Increased costs of logistics, in order to integrate the business service provider effectively with the remaining internal activities of the firm, mean management and administrative functions are not reduced overall. More importantly, there is new empirical evidence to suggest that outsourcing can be detrimental to the innovative capacity of the firms and, hence, have a negative impact on its long-run productivity growth.

Section 4 describes the simulation model that is used to investigate this long-run phenomenon. The section specifies the alternative strategies for organisational innovation available to the firm, the way in which learning is modelled, and the decision rules for adopting new ICTs and outsourcing activities. Section 5 discusses the outputs generated by the simulation model. The results make clear the manner in which the outsourcing of activities restricts the long-term opportunities for organisational innovation, leading to lower productivity growth. Section 6 pulls together the overall findings of the chapter and points to interesting directions for further research. 


\section{Organisational innovation}

The goal of organisational change is the identification of an organisational design that more effectively integrates all the administrative activities of the firm. An organisational design is a hierarchial structure that solves two key problems faced by managers. The first is the 'fundamental coordination problem', namely, how to most effectively organise the value-adding activities and information flows of the firm in order to maximise profit. In addition, managers need to resolve the 'agency problem': to realise and enforce coordination and control in production, both internally and across the boundary of the firm.

Organisational innovation involves the search for new organisational designs that alter the internal organisational structure of the firm, and change the boundary between the firm and markets (verticalisation / de-verticalisation). As just described, it is a search process that is conducted within a complex search space containing many dimensions, and in which the dimensions are related to one another in highly non-linear ways. Dealing with this organisational complexity requires managers to engage in ongoing strategic experimentation and learning. It is this ongoing problem-solving activity that drives organisational change and innovation over time.

Our analysis is based on a modular theory of the firm, developed in recent work by Langlois and Robertson (1995), Baldwin and Clark (1997), Langlois (2002, 2003), and Marengo and Dosi (2005). The theory brings together Adam Smith's principles of specialisation and the division of labour (Smith, 1776), and Herbert Simon's discussion of complexity and the near-decomposability of complex problems (Simon, 1996; 2002), and provides a useful means of discussing organisational change and innovation. We will use this theory to identify the set of conditions under which modularisation is associated with outsourcing to specialist KIBS, and to consider the impact of new ICTs on the decision to outsource.

Simon $(1996,2002)$ provides an important insight into problem-solving activity in general. He provides us with an idea of how problem-solving activity occurs in complex systems. Simon suggested that complex problems can be made more manageable by breaking them down into a set of constituent parts, or 'modular components'. In this way, the number of distinct elements in a system is reduced by grouping them into a smaller number of sub-systems. The great advantage of modularisation is that improvements can be made to one sub-component of the system without the need to change all other parts of the system (as would be the case if there were no modularisation). There is a cost, however. These are associated with the establishment and maintenance of organisational interfaces between sub-components. These interfaces enable a sub-component to function compatibly with all sub-components. This ensures the organisational structure as a whole functions in an integrated way, while maintaining a high degree of independence for each subcomponent.

Smith's principle of specialisation through the division of labour is a way of dealing with this problem-solving activity. Smith's classic example is the pin factory. A range of complex valueadding processes are broken down and divide up into a finer set of specialised functions. This specialisation raises the efficiency of production. Although Smith's example is of specialisation in the organisation of production, the principle holds equally specialisation in the organisation of administration (our current focus). Firms engage in continual, ongoing experimentation in all aspects of the organisation, not just production. This includes decisions about what to produce, the inputs that are required, what should be produced in-house or bought in markets, the geographical location of production, sales etc., the appropriate organisation structure of the firm, and the information and communication requirements of the organisation. Placing Smith's discussion within Simon's framework of decomposable complex problems, the issue facing firms is a process of problem decomposition - of decomposing a system into subsystems. The task becomes one of identifying subsystems, establishing linkages between distinct subsystems, and understanding, managing and codifying their interactions. The problem then facing managers of the firm is, first, how to 
decompose its value-adding activities and, second, how to coordinate the subsystems. Through successful modularisation, a complex system is then transformed into a nearly decomposable one.

To this theory we add the concept of 'system economies' introduced by Nightingale et al. (2003). Our interpretation of system economies are mostly due to improvement in the control of a given set of productive activities and, hence, operate at the meta level. Managers of the firm seek to improve productivity reorganising way in which these value-adding activities interact. This productivity improvement is gained through the design of a more effective organisational design. Organisational innovation, the process through which new designs are arrived at, involves either splitting the administrative tasks into more organisational modules or, alternatively, the integrating of organisational modules to increase control of the modular elements and their interaction. A superior organisational design improves the coordination and control of goods, traffic, materials, funds, services, and information that flows through the complex supply, production and distribution activities of the firm. In this way, better organisational designs (i.e. more effective modularisation schemas) increase the productive utilisation of the firm's installed productive capacity. Innovation begets further innovation over time. Through organisational innovation, managers gain a more specific view of the different activities of the firm, and see the potential creative opportunities that arise through breaking down 'departmental silos' and creating novel synergies activities (i.e. new organisational combinations). For example, creating stronger interactions between the sales and production departments can lead to new product opportunities being realised. These in turn may lead to economies of scope and, if able to develop new markets, economies of scale. This picks up on the pint made by Baldwin and Clark (1997), that the more modular the organisational design, the greater the likelihood of stimulating new inventions, i.e. innovation in products/services, distribution, and the other key value adding activities of the firm.

We suggest that the extent of organisation specialisation ultimately depends on a number of demand and supply side factors. On the demand side, it will depend on the extent of the market (i.e. increases in population and income), and the degree of competition (the elasticity of demand) (Young, 1928). On the supply side, it is affected by the availability of ICTs that enable activities to be subdivided and coordinated, and which enable managers to deal with the agency problem. To do this, managers must be able to generate information on the parts of the organisation for which they are directly responsible, and to exchange between them information about different parts of the organisation. Together, the demand and supply side factors determine the extent to which activities can be effectively modularised and technical hierarchies established.

A number of issues can be discussed within this theoretical framework. To start with, the framework clarifies the relationship between new ICTs and more effective administrative control leading to system economies. The application of new, improved ICTs enable further modularisation of the organisation to occur by lowering the cost of managing and controlling information, leading to increased system economies ${ }^{3}$. It was Chandler $(1962,1977)$ who first claimed that technology directly affects organisational structure. His observation goes to the heart of our discussion. New ICTs alter the set of feasible technological opportunities in production and the division of labour (the fundamental coordination problem), and the opportunities for effective coordination and control within and across the boundary of the firm (the agency problem). These alter the relative efficacy of holding activities in-house and outsourcing. Depending on the particular vintage of ICTs, technological opportunities and cost reductions may stimulate verticalisation or de- verticalisation.

Internet-based ICTs enable the external coordination costs of the firm to be significantly reduced. This opens up new opportunities outsourcing within new, for experimental organisational designs. Over the last decade, a new generation of 'networking' ICTs (built on open web and internet

\footnotetext{
${ }^{3}$ Brynolfsson and Hitt (2000) studied the impact of large ICT investments over the last decades on productivity. They find that, on their own, costly investments have little impact on productivity. They do, however, have very significant impacts on productivity when they are matched with complementary changes in the orgnaisational design.
} 
protocols) have provided the means by which firms can radically reorganise both interactions with firms along the supply chain. It has opened up previously inconceivable levels of interaction between companies. This includes new opportunities for outsourcing to specialist KIBS providers. The networked corporation has emerged as a consequence of inter-firm networking activities along the supply chain. There is a flattening of the hierarchy of the firm, a tendency towards vertical disintegration, and for individual business units to become smaller in size.

It is important to note that the relationship between new ICTs and outsourcing is not simple. Certain types of new ICTs may decrease the costs of internal as well as external costs of communication. Internet technologies, for example, lower the cost of internal administration (through applications such as intranets) as well as reducing the administration cost of external interaction. Others reduce internal costs only. As discussed by Reinstaller and Hölzl (2004), ICTs that were limited in their application to internal administrative activities (such as calculators, typewriters, Hollerith electric tabulating machines, and book-keeping machines) played an important role in the development of uform and m-form hierarchies. Chandler (1977) and Yates (2000) have discussed the way in which these technologies were essential for the emergence of the modern hierarchial organisation in the period between the 1850s and the 1930s. Large corporations were the key purchasers of these new ICT1 technologies, and these technologies in turn further enhanced their ability to grow in size, with a tendency towards vertical integration and the greater centralisation of activities by bringing activities in-house, increasing the hierarchy within the firm.

A second issue that is of central in this chapter is the long-run implications of outsourcing for firm performance. On the one hand, as discussed, internet-based technologies reduce the cost of setting up organisational and information interactions with KIBS. This makes possible the outsourcing of activities that can be delivered more cheaply by the external supplier. At the same time, outsourcing reduces the internal administration overhead of the firm. However, there are limits to the benefits of modularisation. To start with, while internal administration overheads are reduced, external administration overheads rise because an effective interface with the external provider needs to be set-up and maintained. The net benefit, in terms of administrative overheads, depends on whether the cost of the external interface is greater or less than the cost of the internal interface. This is the non-separability effect discussed by Steinmueller (2003), and Miozzo and Grimshaw (2005). They suggest that the governance structures that oversee the interface interactions between client and supplier represent large, sunk investments. Consequently, suppliers are not easily substituted.

A more important potential downside is the impact of outsourcing on the client's long-run potential for organisation innovation and, hence, on its long-run productivity growth. To understand this, let us apply the transmission mechanism just discussed. If new, internet-based ICTs significantly reduce external administration costs compared to internal administration costs, there is a stimulus for outsourcing. However, by outsourcing, the set of internal activities under the direct management of the firm is reduced. This reduces the set of modular elements with which managers can experiment and innovate to create new, more efficient organisational designs. In the long-run this can lead to a lower productivity growth of the client firm. Prencipe (1997) and Brusoni et al. (2001) stress the need to retain control over R\&D, not just for the activity itself, but because it is important to maintain control of the coordination of R\&D, design and manufacturing activities.

\section{Potential advantages and potential costs of outsourcing}

The 1990s saw a dramatic rise in the number of specialised business service firms. The sheer range of activities that are being outsourced is highlighted by McCarthy's 2002 study of outsourcing by US firms. These activities not only include basic back-office activities such as payrolls, they also include advanced, back-office activities such as legal services, and client-facing front-office activities in sales and marketing. The share of activities being outsourced by the firms in this study is presented in Figure 1. 


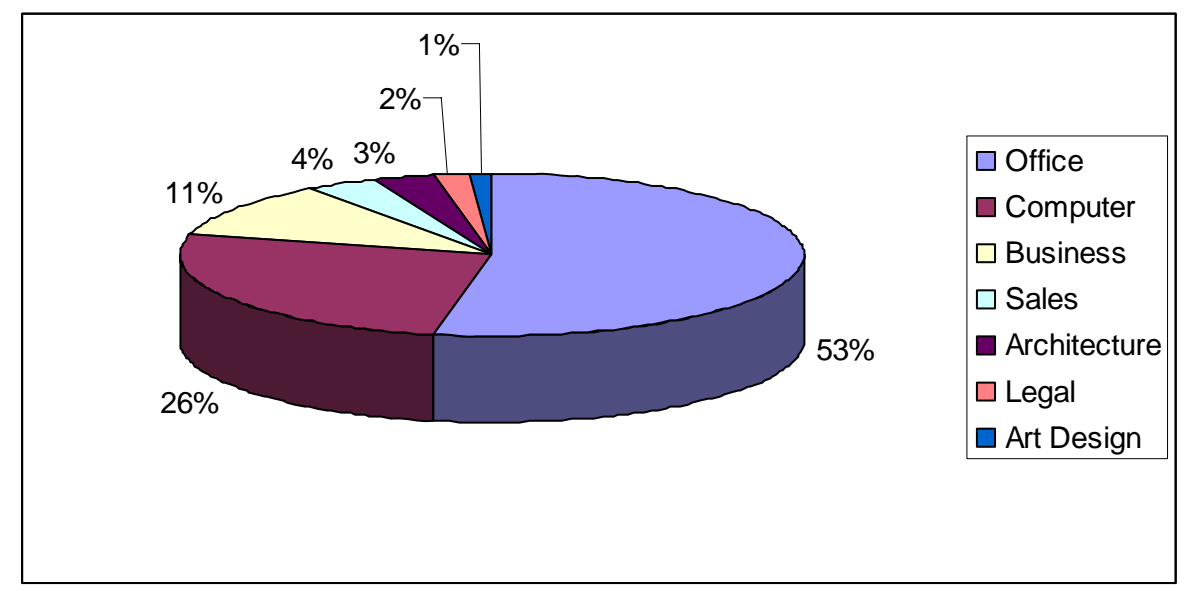

Figure 1. Variety of activities being outsourced Source: McCarthy, 2002

The purchase of the business services from external providers raised the performance of client firms in both services and manufacturing. While acknowledgement of the role played by business services in economic development is not new (see, for example, Greenfield, 1966), empirical studies of their impact are new. For example, Windrum and Tomlinson (1999) tested the contribution to services and manufacturing sectors of knowledge-intensive business services (KIBS) such as business consultants, financial services, and ICT services. Using input-output data from 1970 to 1990, they examined Germany, Japan, the Netherlands, and the UK. KIBS were found to have a positive impact on both service and manufacturing sectors in all four countries over the twenty-year period. Similar findings have been identified in studies by Drejer (2001), Peneder et al. (2003) and Tomlinson (2003). So, while the use of business services has grown rapidly, their use is not new.

A number of studies have sought to identify the key drivers for outsourcing. One of the best known is in the Morgan Chambers study of FTSE 100 firms (Morgan Chambers, 2001). In addition, there is The Outsourcing Institute's study of outsourcing in Japan (Outsourcing Institute, 2005). Taken together, these studies present a remarkably consistent picture. These are presented in Table 1 below. We see that the top three ranked drivers are the same in each study. These are, in order, the reduction of operating costs, improving the focus of the business through a reorganisation of the activities that are conducted in-house and those that are externally sourced, and access to skills and technologies that are not held in-house. In both surveys, these three drivers together accounted for more than $60 \%$ of all responses.

\begin{tabular}{ll}
\hline \multicolumn{1}{c}{ Morgan Chambers study } & \multicolumn{1}{c}{ Outsourcing Institute study } \\
\hline Cost saving & Reduce and control operating costs \\
Focus on core business & Improve company focus \\
Access to skills and technology & Gain access to world-class capabilities \\
Risk management & Free internal resources for other purposes \\
Quality service improvement & Resources are not available internally \\
Change enabler & Accelerate reengineering benefits \\
Business development & Function is difficult to manage/ out of control \\
Other & Make capital funds available \\
& Share risks \\
& Cash infusion \\
\hline
\end{tabular}

Table 1. Drivers of outsourcing, by rank

These three key drivers have also been highlighted in the literature on knowledge-intensive business services (KIBS). KIBS provide their clients with high quality information on new business opportunities, new trends in the market place, and the business potential of new technologies, such as new ICTs. Through the outsourcing of specific inputs to KIBS, clients can improve productivity and 
competitive performance as existing in-house inputs are substituted for higher-quality, externally sourced inputs. Third, KIBS are exemplars of novel business models. They provide a concrete illustration of new business models and, through their ongoing relationship, introduce clients to these new ways of working and new technologies. Antonelli (1998), for example, has highlighted the role of KIBS on the diffusion of new ICTs. KIBS are leading advocates of new, internet-based technologies because these technologies enable them to more effectively interface with clients and, as a consequence, to more effectively intermediate experience, information and knowledge between clients. In this way, KIBS have become key intermediaries, improving the efficiency and speed of learning within innovation networks.

As noted in section 2, there exist a set of potential disadvantages associated with outsourcing. These can have negative long-run implications for organisation innovation and, hence, long-run productivity growth. Let us discuss these in detail. An empirical study based on a large scale survey of medium and large size Swedish manufacturing and service firms ${ }^{4}$ has been conducted by Bengtsson and von Hartman (2005). They found that companies' evaluations of the direct effects of outsourcing, e.g. cost reduction through the reduction of direct personnel, were fulfilled. However, management and administrative functions were not reduced. Indeed the firms report a strongly negative impact of outsourcing on logistics - e.g. manufacturing lead times, delivery times and accuracy. They also report negative impacts on quality and adaptation to customer demands. These key findings indicate that outsourcing is accompanied by more complex logistics, increasing the internal administrative overhead. Bengtsson and von Hartman report that these logistics problems were more common among amongst companies that outsource to low-cost countries.

These findings are supported by research conducted by others authors. First, it is observed that the contract needs to be monitored and measured carefully. This can prove expensive, and increasingly expensive if skills in the client firm are lost over time (Domberger, 1998). Second, governance inseparability between client and supplier means considerable investment in interpersonal and administrative relations between the firms is necessary in order to support the new division of labour (Steinmueller, 2003; Miozzo and Grimshaw, 2005). Third, poorly delivered services will negatively affect the client's production or, where end-user services are delivered, the client's brand and reputation (Hinks and Hanson, 2001). Fourth, the security of sensitive information needs to be considered, with an increased risk of exposure of the clients' sensitive internal information (Mylott III, 1995). Fifth, there are well documented cases of knowledge and information, acquired by the service provider, being shared with the clients' competitor firms. Clients believed that services and information would be proprietary, while the service providers saw the transactions as the basis for further business within the client's industry.

Of course, it is not just low-skilled activities that are being outsourced. Complex production and advanced R\&D are also being outsourced. The inseparability of ICT from production means suppliers are not turn-key, i.e. they cannot be easily substituted (Miozzo and Grimshaw, 2005). Prencipe (1997) highlights the dangers of outsourcing activities based on simple notions of core and non-core competences. The outsourcing of what today appear to be non-core competences can seriously impair the development of new (core) technological competences in the future. Separation of development and production hampers innovation. Brusoni et al. (2001) emphasise the importance of retaining control over $\mathrm{R} \& \mathrm{D}$, and the ability to coordinate the $\mathrm{R} \& \mathrm{D}$, design and manufacturing activities of suppliers.

To summarise, a growing body of empirical research exists which suggests that the short-run gains of outsourcing may be more than offset in the longer term, leading to lower long-run productivity growth. We have formulated a theoretical framework for understanding these dangers; one that links organisational innovation with the adoption of new ICTs and with outsourcing opportunities. The framework enables us to identify a specific transmission mechanism between ICT adoption,

\footnotetext{
${ }^{4}$ The analysis is based on a set of completed written questionnaires from 267 firms. All firms have more than 50 employees and are drawn from the ISIC sectors 28-35: metal goods, machinery, office equipment and computers, other electronics, telecoms, instrumentation, and automotive industry.
} 
organisational innovation and outsourcing. Further, the framework explains why outsourcing can negatively impact organisational innovation and productivity in the long-run. Specifically, the outsourcing of activities reduces the total set of modular elements that can be experimented with in the future. With less components under their control, managers are unable to experiment with all possible organisational combinations. The danger is that this puts out-of-reach the discovery of more efficient organisational designs. Hence, the firm can become locked in to a suboptimal design space. If this is the case, then the outsourcing firm will suffer lower growth in productivity than if it had not outsourced (and the entire space of organisational designs could have be explored).

\section{The model: hierarchy, profitability and information technologies}

In this section we develop a simulation model that captures some of the core ideas of modularity in organisations presented in the previous sections, and study how ICTs and outsourcing of business services may affect the long-run performance of a firm. For this purpose we define the organisation as a complex system. The management seeks to improve this system by searching for better organisational designs. As firms are boundedly rational this happens through learning from past experiences in organisational restructuring.

\section{Administration}

Figure 2 shows how we conceptualise an organisational design. We assume the administration of a firm delivers services to productive activities that eventually generate the value added generated of the firm. The quality of these services, $\theta_{1}$ to $\theta_{4}$ in Figure 2, has an impact on the performance of productive activities. These services are produced by organisational activities $m_{1}$ and $m_{2}$ (see Figure 2a) which produce a subset of all services. More generally, the organisation of a firm consists of a set of $n$ organisational modules or activities $m_{i}$ grouped into an organisational design $d=<m_{1}, m_{2}$, $\ldots, m_{n}>$ that delivers a vector $\theta$ of $k$ services to productive activities in the firm. The array $d \in D$ corresponds to one organisational design, which is drawn from of a finite space $D$ of organisational designs, which the management explores over time.

Each of the activities present in a design consists of $\lambda_{i}$ sub-activities or $m_{i}=<x_{k}>_{h=1}^{\lambda_{i}}$. The number of sub-activities $\lambda_{i}$ in each of these modules may vary, but we assume that each affects exactly one of the $k$ output characteristics. Each larger activity in turn affects some subset of the services to the productive activities. Together these output characteristics meet well defined customer needs in the market where the firm operates. In our model the organisation of a firm is therefore defined through the characteristics of an organisational design $d$ given by $n$ organisational modules $m_{i}$ and $k$ service characteristics. The number of modules $n$ is a measure of the degree of decomposition of organisational activities.

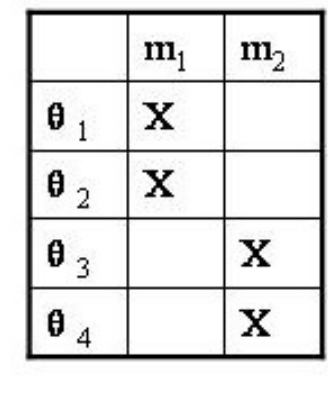

a)

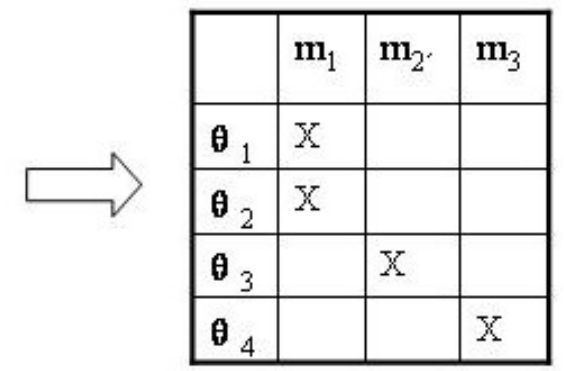

b)

Figure 2. Interdependence and modularity in organizational designs 
The sub-activities $x$ in each module $m_{i}$ are strongly related to one another, i.e. the performance of each sub-activity $\phi\left(x_{k}\right)_{t}$ at time step $t$ affects the performance of all other sub-activities in the module and its performance is in turn influenced by all other sub-activities in the module. This implies that the total performance of a module $\phi\left(m_{i}\right)_{t}$ changes if $\phi\left(x_{k}\right)_{t}$ changes. The modules $m_{i}$ themselves are linked through organisational and technical interfaces that neutralise the strong complementarities that persist between the sub-activities within each module. These interdependencies reflect a situation that is typical in team production, where the skills and activities of the members in a team are closely complementary and integrated. So, if one member performs under par, the work efficiency of all other members is affected. This is shown in Figure 2. If the management wants to improve service $\theta_{3}$ produced in organisational module $m_{2}$ then changing the work profile of the related activity $\mathrm{x}$ will actually imply the performance of the sub-activity producing service $\theta_{4}$ is also affected. In the simulations we will determine $\phi\left(m_{i}\right)_{t}$ by drawing $\lambda_{i}$ values from a uniform distribution with $\phi\left(x_{k}\right)_{t} \rightarrow$ Uniform[0,1] and calculating the average over the $\lambda_{i}$ subactivities. The impact of all $n$ service producing administrative activities on firm performance is then given by, $\Phi_{t}=\frac{1}{n} \sum_{i=1}^{n} \phi\left(m_{i}\right)_{t}{ }^{5}$

In Figure $2 \mathrm{~b}$ the problem of strong complementarity is resolved by splitting module $m_{2}$ into two distinct sub-activities where each is focused on producing exactly one service. The coordination problem between the two sub-activities is solved by introducing a coordination mechanism between the two. Therefore the hierarchy increases and the co-ordination overhead increases. This captures Simon's (1996) idea of realising near-decomposable designs in order to control complex problems better. In this process economies of system are realised.

\section{Organisational learning: exploitation vs. exploration}

The management of the firm is assumed to use a set of strategies $S$ to explore the space of organisational designs $D$. The strategy space $S=\left(s_{1}, s_{2}, s_{3}\right)$ consists of three strategies, each of which is used with probability $\mu_{j}$ at each time step $t$. The firm pursues them to improve administrative services that have an impact on the performance of productive activities. The first strategy $s_{1}$ corresponds to learning by doing. In this case all values for $\phi\left(x_{k}\right)_{t+1}$ are redrawn, and if the average over the $\lambda_{i}$ sub-activities increases this will correspond to a performance improvement. The second and the third innovation strategies involve changing the organisational design of the firm. This is illustrated in Figure 3. The firm may engage in identifying and neutralising some of the complementarities that bind sub-activities into a module. This may enable it to split a more complex activity into a number of less complex activities and redesign its organisation accordingly. This decomposition strategy $s_{2}$ is called 'splitting'. It corresponds to the development of a neardecomposable design of administrative activities. Finally, it may pay the firm to redesign its production and organisation by organising smaller activities into larger and more complex modules. It is the reverse strategy of decomposition. It involves the selective acquisition of complementarity relationships between previously unrelated activities, say by supporting the development of synergies. This integration strategy $s_{3}$ we call 'job-enrichment'. In both $s_{2}$ and $s_{3}$ the organisational design is changed, with poorly performing activities replaced by better performing ones ${ }^{6}$. In this case all

\footnotetext{
5 This representation of organisational designs and their impact on the performance of productive activities corresponds to a generalised NK model (see Altenberg,1995).

${ }^{6}$ Decomposition and integration have been discussed as possible evolutionary mechanisms of change in the realm of genetics by Wagner and Altenberg (1996).
} 
performance values $\phi\left(x_{k}\right)_{t+1}$ for the elements in the new module(s) are redrawn and if their joint average increases this will again correspond to a performance improvement.

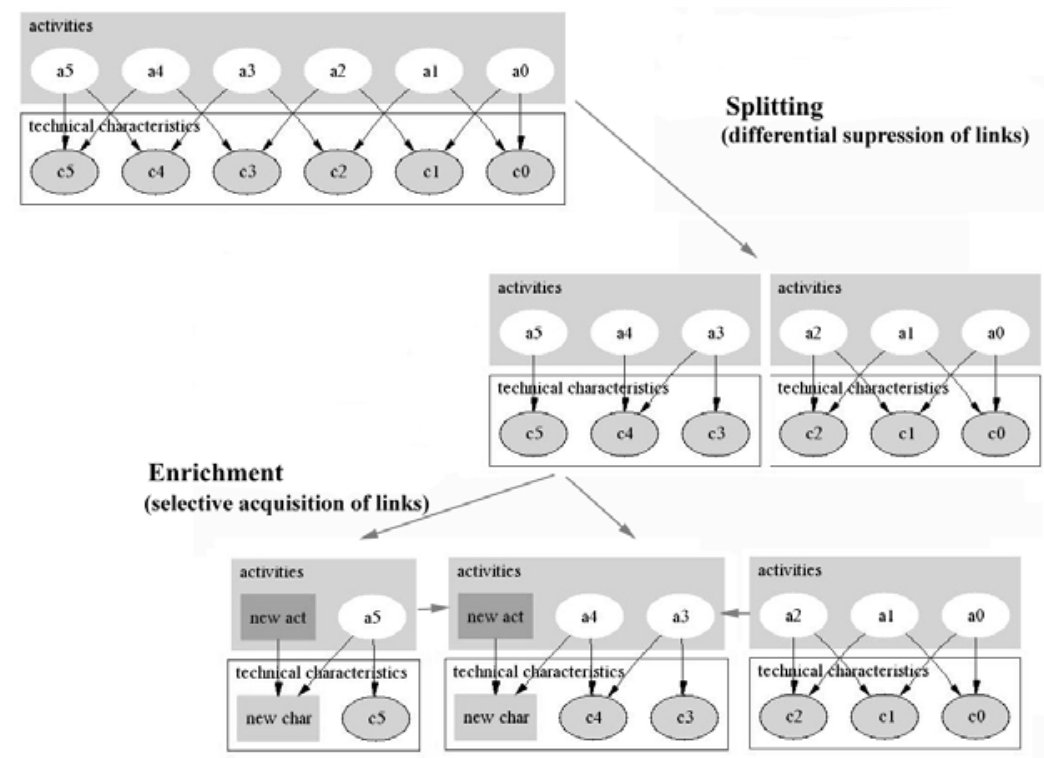

Figure 3. Splitting and enrichment as strategies in organizational re-design

These strategies are assumed to affect the performance $\Phi_{t}$ of productive activities through economies of system, i.e. by allowing for better control of productive activities and therefore pushing productivity for a given technology towards its limit.

As discussed earlier, the literature on modularity advances the argument that an increase of the modularity of a system leads also to an improvement in the innovation rate. The basic idea behind this is that modularity allows a better understanding of the workings of a system and therefore increases the chance that better ways of doing things are discovered. In our case we will assume that, depending on the degree of decomposition of the administration of the firm given by the number of activities $n$, the likelihood that better ways of organising the production process are discovered increases if the firm invests into this process of exploration. This will push ahead the performance $\Phi_{t}$ of productive activities by a factor $\left(1+\varepsilon_{t}\right)$, where $\varepsilon_{t+1}=\varepsilon_{t}(1+\tau)$. In the simulation, parameter $\tau$ has a small positive value as does $\varepsilon_{t}$ at $t=0$. The probability of the firm making an innovation $\varepsilon_{t}$ is determined by a Poisson process with an arrival rate $\alpha$. Following Silverberg and Verspagen (1994), we assume the firm's investments have first increasing and then decreasing returns, which are reflected in a logistic representation of the arrival rate given by

$$
\alpha_{t+1}=\frac{\alpha_{\min } \alpha_{\max }}{\alpha_{\min }+\left(\alpha_{\max }-\alpha_{\min }\right)^{-\left(r^{*} n_{t}\right)}} .
$$

Here $\alpha_{\min }$ represents a small autonomous probability of making a fortuitous innovation without investing in this type of innovation, and $\alpha_{\max }$ corresponds to an asymptotic saturation level of the arrival rate. As can be seen, this process depends on the propensity to invest (r) and on the degree of decomposition, which essentially captures the innovation potential. 
The behaviour of the firm is given by the probability distribution over its three actions. The innovation policy mix $s_{t}=\left[\begin{array}{lll}\mu_{1, t} s_{1} & \mu_{2, t} s_{2} & \mu_{3, t} s_{3}\end{array}\right]^{\prime}$, with $\mu_{1, t}+\mu_{2, t}+\mu_{3, t}=1$, that maximises profits $\Pi_{d}\left(s_{t}\right)$, evolves through reinforcement learning given some initial probabilities $\mu_{j, t=0}$. This should not be interpreted as conscious randomisation, rather it indicates (from the perspective of the outside observer) how likely it is that the decision maker will choose each of these three actions. The reinforcement learning dynamics we apply is identical to the one explored by Arthur (1993), where each of the strategies is allocated a strength according to its past contribution to the performance of the firm

$$
\mu_{j, t+1}=\mu_{j, t}+\frac{\Delta \Pi\left(s_{j}\right)_{t}-\mu_{j, t} \sum_{j} \Delta \Pi\left(s_{j}\right)_{t}}{\sum_{j} \sum_{t} \Delta \Pi\left(s_{j}\right)_{t}}
$$

where $\Delta \Pi\left(s_{j}\right)_{t}=\Pi\left(s_{j}\right)_{t}-\Pi\left(s_{j}\right)_{t-1}$ indicates the change in the performance improvement between two time steps $t$ and $t-1$ where strategy $s_{j}$ was used. Equation (1) reinforces the strategies that performed best in the past, i.e. those which previously maximised profits.

\section{Costs of production for a given organisational design}

We assume that white collar activities are not productive in themselves, but that they improve the utilisation and the development of the firm's productive resources. More precisely, we assume that the services produced by an administrative activity $m_{i}$ have an impact on the performance of productive activities, $\phi\left(m_{i}\right)_{t}$. As mentioned previously, the impact on the unit costs of productive activities by all $\mathrm{n}$ modules is given by $\Phi_{t}$. The unit costs of productive activities are then given by

$$
v c_{d, t}=w_{p} l_{p} e^{-\left(1+\varepsilon_{t}\right) \Phi_{t}}
$$

where $w_{p}$ is the average wage bill per unit of output paid for productive activities, and $l_{p}$ is the unit labour requirement.

In the administration of a firm there are two types of activities. The first set of activities produces services for productive activities. The second set of activities coordinate the interaction between these services. Only service producing administrative activities are outsourced as coordination activities typically reflect critical management skills. We also assume that the number of services a module produces is proportional to its skill intensity, i.e. the more services an activity produces, the higher are the skills required to carry them out. This in turn implies that the average wage paid to these activities is higher than to activities where only a few services are produced. For simplicity we assume that the unit wage cost of producing one service to productive activities and that of carrying out one coordination task are the same.

Information technologies affect coordination costs. We distinguish between the cost of internal coordination and the cost of external coordination. Total administrative overhead costs are then defined by

$$
o c_{d, t}=\left(z l_{a} w \bar{\lambda}+(1-z) \sum_{h} p_{h}\right)+l_{c} w\left(v_{\mathrm{int}} e^{-\theta_{\mathrm{int}}}+v_{\mathrm{ext}} e^{-\theta_{\mathrm{ext}}}\right)
$$

where $l_{a}$ and $l_{c}$ are the unit labour requirements for service and coordination activities, $\mathrm{w}$ is the going wage rate paid per "skill unit", $\bar{\lambda}$ is the average number of services produced in each administrative activity, $p_{h}$ are the prices paid for outsourced activities, $v_{i n t}$ and $v_{\text {ext }}$ are the number of internal and 
external coordination activities, and $\theta_{\text {int }}$ and $\theta_{\text {ext }}$ reflect the impact of the use of ICTs on internal and external coordination costs respectively. Variable $z, 0 \leq z \leq 1$, weights the unit costs of production of administrative services produced in-house and those produced outhouse by their respective share in the total number services produced.

We assume a subcontractor typically has a cost advantage in producing a particular service. If a specific service producing administrative module $m_{i}$ is outsourced the unit cost of production of its services by the service firm is then given by

$$
c s_{h}=l_{a, h} w \lambda_{i, h} \gamma_{h}+l_{c, h} w\left(v_{\mathrm{int}, h} e^{-\theta_{\mathrm{int}}}+v_{\mathrm{ext}, h} e^{-\theta_{\mathrm{ext}}}\right),
$$

where $\gamma$ now reflects the comparative cost advantage service firm $h$ has in producing the services of administrative activity $m_{i}$. In the simulations we will assume that $\gamma \rightarrow N\left(1, \sigma^{2}\right)$, i.e. the cost advantage is normally distributed around a mean of 1 (meaning that a-priori there might be no cost advantage) with some variance $\sigma^{2}$. Variables $l_{a, h}$ and $l_{c, h}$ reflect the relative unit labour requirements for service producing and coordination activities and $v_{i n t, h}$ and $v_{\text {ext }, h}$ give the number of internal and external coordination activities the service supplier has to manage. Assuming now that the supplier has some market power such that he is able to charge a positive mark-up $\xi$ over costs then the unit price for the services of supplier $h$ to the outsourcing firm is given by

$$
p_{h}=(1+\xi) c s_{h} .
$$

Finally, we assume that the firm has a certain propensity $r$ to invest part of its revenues into the exploration of innovation potentials due to the modularity of the administration. These costs are then given by

$$
r c_{t}=r p_{t} q_{t}
$$

where $p_{t}$ and $q_{t}$ are the prices charged and the quantities sold at a time step $t$.

\section{Profits}

If the firm acts in an environment in which monopolistic competition prevails, it will face a downward sloping (inverse) demand given by

$$
p_{t}=\frac{I s}{q_{t}^{1 / \eta}}
$$

where $p_{t}$ is the price the firm is able to charge at time $t, I s$ is the amount of income customers spend on the firm's product, $q_{t}$ is the firms output and $\eta, \eta>1$, is the price elasticity of demand. Following standard theory, the optimum output and price for a given organisational design $d$ are given by

$$
q_{t, d}^{*}=\left[\frac{I s(1-1 / \eta)}{v c_{d, t}+o c_{d, t}}\right]^{\eta} \text {, and } p_{t, d}^{*}=\frac{\eta\left(v c_{d, t}+o c_{d, t}\right)}{\eta-1} \text {. }
$$

Therefore, for each organisational design $d$ the firm tries to maximise profits

$$
\Pi_{d}\left(s_{t}\right)=\left(p_{t}^{*}-v c_{d, t}-o c_{d, t}\right) q_{t}^{*}-r c_{t}-c_{t}
$$

by reducing unit costs of production. In our model the firm does this by pursuing different strategies $s_{t}$ of organisational innovation that allow improving the performance of the firm's productive 
activities. The term $c_{t}$ reflects fixed capital cost. We assume that the firm needs to keep its capitaloutput ratio constant and therefore invests or disinvests as output changes.

\section{The adoption and outsourcing decision}

The decision to adopt an organisational innovation, and the decision to outsource, will depend on the economic profitability of doing so. Therefore the management of the firm will calculate the expected profits $E\left[\Pi_{d^{\prime}}\left(s_{t}\right)\right]$ a new organisational design $d^{\prime}$ is likely to generate and compare them with the profits the current design yields. Therefore, the decision rule to adopt a new organisational design $d$ ' is given by the following inequalities:

$$
\begin{cases}\Pi_{d}\left(s_{t}\right) \geq E\left[\Pi_{d^{\prime}}\left(s_{t}\right)\right] & \text { reject innovation } \\ \Pi_{d}\left(s_{t}\right)<E\left[\Pi_{d^{\prime}}\left(s_{t}\right)\right] & \text { accept innovation, }\end{cases}
$$

Depending on the management strategy, a firm may have a certain propensity to pursue outsourcing as a strategy, such that, given strategy parameter $o s, 0 \leq o s \leq 1$, it will calculate the expected profits of outsourcing these services to other firms leading to an organisational design $d$ " with probability $p r_{o s}$

$$
\text { if } p r_{o s}>o s\left\{\begin{array}{lc}
E\left[\Pi_{d^{\prime \prime}}\left(s_{t}\right)\right] \leq E\left[\Pi_{d^{\prime}}\left(s_{t}\right)\right] & \text { inhouse } \\
E\left[\Pi_{d^{\prime \prime}}\left(s_{t}\right)\right]>E\left[\Pi_{d^{\prime}}\left(s_{t}\right)\right] & \text { outsource }
\end{array}\right. \text {. }
$$

These are the decision rules the firm follows in order to improve maximise its profits at each moment in time.

\section{Results}

Using the model, we examined four different scenarios. The parameters used to calibrate the model are given in the appendix. The results of the simulation runs are presented in Figure 4. The plots in the top quadrant of Figure 4 show the development of productivity in the firm. The bold line always represents the mean over 50 runs for each parameter setting, while the thin dashed lines represent the $95 \%$ confidence interval of the results of the runs. The plots in the middle of Figure 4 show the development of overhead costs over time and, finally, the plots in the bottom quadrant show the depth of hierarchy of the firm's administration structure.

The first two scenarios, presented in the left part of Figure 4, juxtapose the impact of ICTs on performance, and the costs of the firm for a given high propensity of managers to choose outsourcing as a strategy. The results for low internal but high external coordination costs are represented by dash-dot-dash lines, while those for equally efficient internal and external communication costs are represented by unbroken lines. 

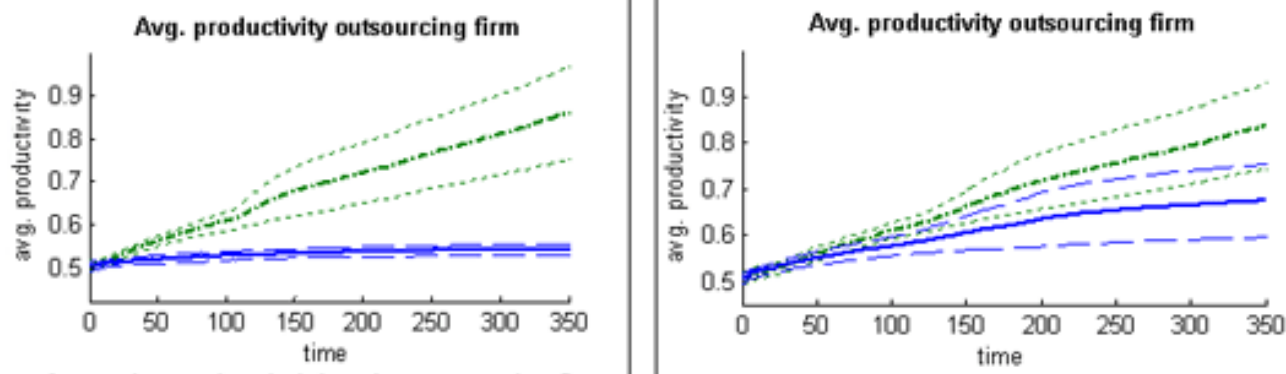

Avg. unit costs in administration outsourcing firm

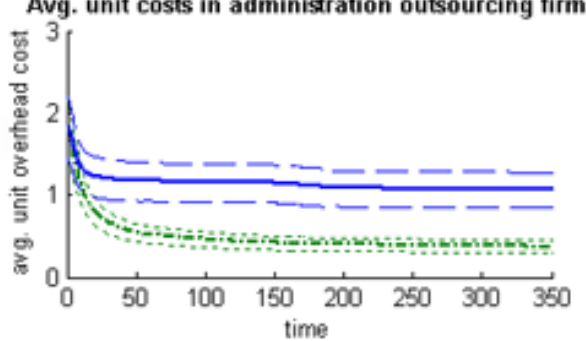

Avg. unit costs in administration outsourcing firm
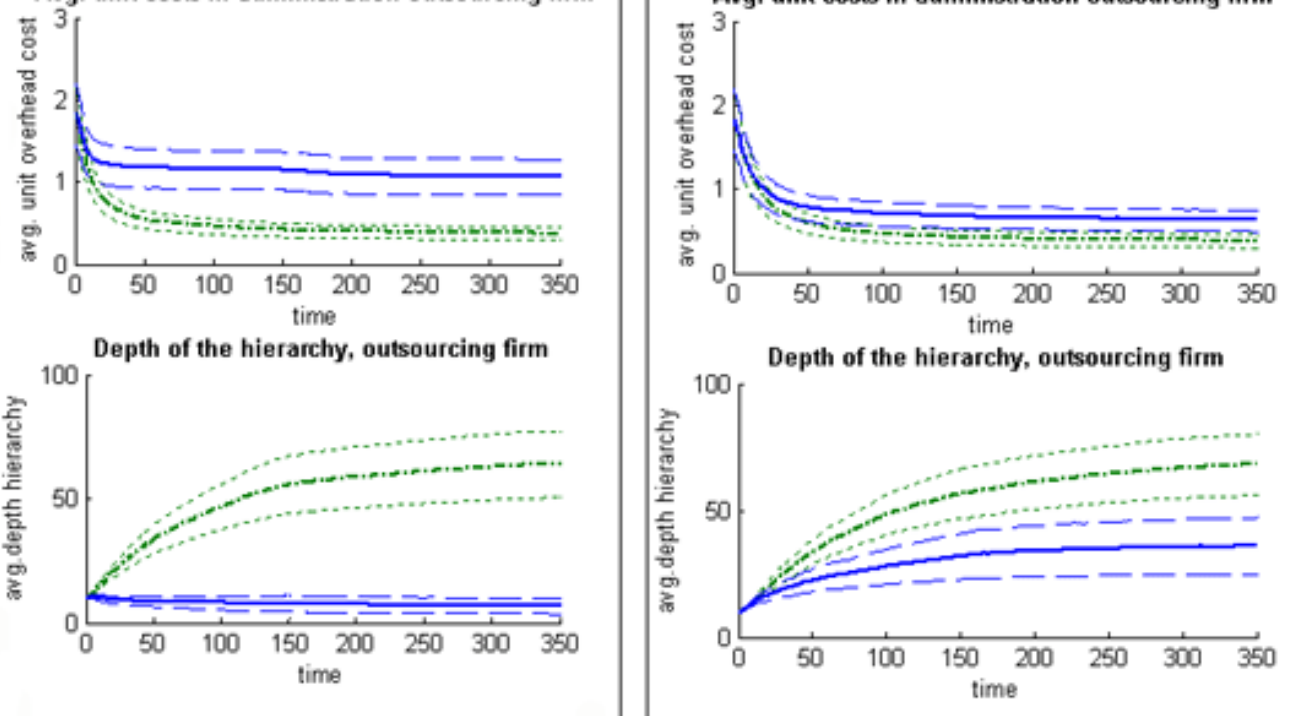

Figure 4: Simulation runs. Left: scenario with high outsourcing propensity by management. Right: scenario with low outsourcing propensity by management. Dash-dot-dash lines represent runs with low internal communication costs only for a given outsourcing propensity. Unbroken lines represent runs with low internal and low external communication costs for a given outsourcing propensity. The bold lines represent means over 50 runs, the thin dashed lines $95 \%$ confidence intervals around these means.

The findings suggest that a high outsourcing propensity, supported by low external coordination costs, lead to a paradoxical development. The firm performs worse in the long-run if external coordination costs fall. The explanation for this apparent paradox is as follows. Managers of the firm are myopically learning over time. They do not have information on the payoffs of all possible choices, and are unable to observe the pay-offs of firms that choose a different strategy. Hence, they are only able to observe the payoffs associated with their own past choices. In other words, managers of the firm are engaged in pure learning-by-doing. In practice, this is reasonable approximation of the reality for managers in the vast majority of firms. Unlike physical products and services, which can be obtained and reverse engineered, managers do not have ready access to information on the other firms' organisational structures, administrative services, and the performance of those organisational structures.

Under these circumstances, the managers of the firm perceive there to be cost-cutting potentials if ICTs lead to a fall in external coordination costs, and proceed to outsource a high number of service activities. As a consequence, the depth of the hierarchy is reduced and in the beginning overhead costs drop as well. Productivity also grows initially. It grows at a much slower rate than if the firms had not outsourced, but of course the firm will not actually 'see' this in practice because it has chosen to pursue the alternative trajectory of outsourcing. Unfortunately, as the firm continues along this path, productivity growth continues to fall and can even stagnate. The upshot is that managers 
focused on the short-run cost cutting effect will succeed in reducing costs, but unwittingly reduce the long-run innovation potential of the firm as well.

An alternative scenario is that the new ICT lowers internal coordination costs. This supports the development of increased modularity in the administration of the firm. As the activities become more specialised, it is easier to improve the quality of their service to the productive activities. At the same time, the long run potential for radical organisational innovations is exploited successfully. The longrun productivity of the firm under this scenario outperforms alternative scenarios where external coordination costs are lowed by new ICTs and firms engage in outsourcing. These results lend support to the thesis that the 'quick-fix' strategy, to outsource in order to reduce costs, endangers the long-run performance and survival of firms.

On the right hand side of Figure 4 we present the results for the scenarios where outsourcing propensities are low. Again, we consider what happens if ICT reduces external coordination costs and what happens if ICTs reduce internal external coordination costs. Once again, the finding is that ICTs which stimulate internal organisational innovation outperform the scenario where ICTs stimulate outsourcing. As before, the reason is that the long-run productivity potential of the firm depends on the degree of decomposition of administrative activities. Therefore firms always fare better in the long-run if they keep the service activities in-house and reap all the benefits of the process of organisational innovation. Once activities are outsourced, suppliers in our model charge a constant price and no longer improve the quality of the services they deliver. As a consequence, producing services in-house is the dominant strategy in this simulation.

The results seem to mirror the observations of the empirical studies discussed in section 3 . However, it is important to observe that long-run productivity of the runs with low external coordination cost comes close to the long-run productivity levels where external coordination costs are high in the upper end of the confidence interval. This outcome depends on the propensity of the firm to invest in radical organisational innovation. It suggests that, if a firm chooses to (moderately) outsource and is inclined to do so by low external coordination costs, it should scale up its investment in radical organisational innovations, which will better exploit the innovation potentials.

\section{Conclusions and directions for further research}

The chapter has investigated the thesis that outsourcing activities to business services (KIBS) can cut certain types of administrative costs but that they may reduce productivity growth in the long-run. This is the striking thesis that is emerging from the latest empirical research on the long-term impacts of outsourcing on the innovative capabilities and productivity growth of client firms. The chapter summarised the short- and long-term costs and benefits of outsourcing, and proceeded to place them a more analytical footing through the development of a framework of organisational innovation that integrates decisions to outsource with the introduction of cost saving new ICTs. The framework specified a transmission mechanism that explains the links between the adoption of new ICTs, alternative strategies for organisational restructuring, system economies and the decision to outsource.

The framework has been implemented in a novel model of organisational innovation. Simulations conducted on this model enabled us to consider the short- and long-run impacts of outsourcing on administration overheads and on long-term productivity growth. The interesting finding is that managers of a firm can become locked into a low productivity growth trajectory, associated with the outsourcing of activities, if they are myopic and learn through their own actions. They perceive outsourcing to cut overhead costs in the short-run (as expected), and so engage in further outsourcing thereafter. This is to the detriment of long-run productivity gains (system economies) generated though organisational innovation. This occurs because the potential for organisational innovation is reduced when modular components are outsourced, placing them beyond the control of the firms' management. The findings accord well with the empirical data, and provide a salutary warning for managers and policy-makers about the potential long-term implications of outsourcing. 
Looking forward, there are clearly a number of limitations in the current model and a need for extensions to be made in the future. The results hinge upon a number of simplifications. In our model, outsourcing is a purely cost driven process and important potential interactions between suppliers and service firms, as well as the exchange of competencies, are neglected. Therefore the model presents a perspective where service suppliers just offer a cost cutting potential once, but afterwards do no longer interact with their customer on service improvements. This is not always the case with KIBS, even though some of the empirical literature we have discussed suggests that this problem does exist. In future research we will explore the alternative case, where the interaction between service suppliers and firms stretches to the process of organisational innovation. Another limitation of the current version of the model is that it ignores potential conflicts and organisational resistance to change. These may play an important role in management decisions, and are also likely to have an impact on the long-run productivity of firms. In this model, the development of a neardecomposable administrative hierarchy is a frictionless process with perfectly flexible labour markets. Further research needs to address this set of questions as well.

\section{References}

ALTENBERG L., 1995, Genome growth and the evolution of the genotype-phenotype map, in: W. Banzhaf and F.H. Eckman (eds.), Evolution and Biocomputation, Berlin \& Heidelberg: Springer-Verlag, 205-259.

ANTONELLI C., 1998, Localized technological change, new information technology and the knowledge-based economy: the European evidence, Journal of Evolutionary Economics, 8 (2), 177-198.

BALDWIN C.Y. AND K.B. CLARK, 1997, Managing in an age of modularity, Harvard Business Review, 75 (5), 84-94.

BENGTSSON, L. AND L. VON HARTMAN, 2005, Outsourcing manufacturing and its effect on firm performance, Paper presented at CINet, Brighton 4-6 September 2005.

BRUSONI S., PRENCIPE A. AND K. PAVITT, 2001, Knowledge specialisation, organisational coupling, and the boundaries of the firm: why do firms know more than they make?, Administrative Science Quarterly, 46, 597-621.

BRYNOLFSSON, E. AND L.M. HITT, 2000, Beyond computation: information technology, organisational transformation, and business performance, Journal of Economic Perspectives, 117, 339-376.

CHANDLER A.D., 1962, Strategy and Structure, Cambridge, Mass.: MIT Press.

CHANDLER A.D., 1977, The Visible Hand: The Managerial Revolution in American Business. Cambridge, Mass.: Belknap Harvard University Press.

DOMBERGER S., 1998, The Contracting Organization: A Strategic Guide to Outsourcing, Oxford: Oxford University Press.

DREJER I., 2001, Business services as a production factor, CEBR Working Paper 2001-7, Copenhagen: CEBR.

GREENFIELD H.I., 1966, Manpower and the Growth of Producer Services, Columbia, New York: Columbia University Press.

HINKS J. AND H. HANSON, 2001, 'In-house or outsourced? Making the decision', in J. Hinks, and J. Reuvid (eds), Strategies for Outsourcing and Facilities Management: Managing Business Support Service, London: Kogan Page. 41-49.

LANGLOIS R.N., 2002, Modularity in technology and organization, Journal of Economic Behaviour \& Organization, 49, 19-37.

LANGLOIS R.N., 2003, The vanishing hand: the changing dynamics of industrial capitalism, Industrial and Corporate Change, 12 (2), 351-385.

LANGLOIS R.N. AND P. L. ROBERTSON, 1995, Firms, Markets and Economic Change. London: Routledge. 
MARENGO, L. AND G. DOSI, 2005, Division of labor, organizational coordination and market mechanisms in collective problem-solving, Journal of Economic Behavior \& Organization, 58, 303-326.

McCARTHY J.C., 2002, 3.3 million US service jobs go offshore, Techstrategy Brief, Forrester Research Inc, Nov.2002.

MIOZZO M. AND D. GRIMSHAW, 2005, Modularity and innovation in knowledge-intensive business services: IT outsourcing in Germany and the UK, Research Policy, forthcoming, available at www.sciencedirect.com

MORGAN CHAMBERS, 2001, Outsourcing in the FTSE 100, available at www.cw360.com/outsourcingreport.

MYLOTT III T.R, 1995, Computer Outsourcing: managing the Transfer of Information Systems, New Jersey: Prentice Hall.

NIGHTINGALE, P., BRADY, T., DAVIES, A. AND J. HALL, 2003, Capacity utilisation revisited: software, control and the growth of large technical systems, Industrial and Corporate Change, 12 (3), 477-517.

OUTSOURCING INSTITUTE, 2005, New Workplace: Outsourcing in Japan, available at www.outsourcing.com

PENEDER M., KANIOVSKI S. AND S. DACHS, 2003, What follows tertiarisation?: structural change and the role of knowledge-based services, The Service Industries Journal, 23 (2), 47 66.

PRENCIPE A., 1997, Technological competencies and product's evolutionary dynamics: a case study from the aero-engine industry, Research Policy, 25, 1261-1276.

REINSTALLER A., AND W. HÖLZL, 2004, 'Complementarity constraints and induced innovation: some evidence from the first IT regime', in Applied Evolutionary Economics and Complex Systems, J. Foster, and W. Hölzl (eds.). Cheltenham: Edward Elgar, 133-54.

SILVERBERG G. AND B. VERSPAGEN, 1994, Collective learning, innovation and growth in a boundedly rational, evolutionary world, Journal of Evolutionary Economics 4, 207-226.

SIMON H.A., 1996, 'The architecture of complexity: hierarchical systems', in The Sciences of the Artificial, H. A. Simon (ed.). Cambridge Mass.: MIT Press, 183-216.

SIMON H.A., 2002, Near decomposability and the speed of evolution, Industrial and Corporate Change, 11, 587-99.

SMITH A., 1776, An Enquiry into the Nature and Causes of the Wealth of Nations, Oxford: Clarendon Press.

STEINMUELLER, W.E., 2003, The role of technical standards in co-ordinating the division of labour in complex system industries, in A. Principe, A. Davies, and M. Hobday (eds.), The Business of Systems Integration, Oxford: Oxford University Press.

TOMLINSON M., 2003, A New Role for Business Services in Economic Growth, in D. Archibugi and B. Lundvall (eds.), The Globalizing Learning Economy, Oxford: Oxford University Press.

WAGNER G.P. AND L. ALTENBERG, 1996, Perspective: complex adaptations and the evolution of evolvability, Evolution, 50, 967-976.

WINDRUM P., AND M. TOMLINSON, 1999, Knowledge-intensive services and international competitiveness: a four country comparison, Technology Analysis and Strategic Management, Vol. 11 (3), pp. 391-408.

YATES, J., 2000, Business Use of Information and Technology during the Industrial Age, in A Nation Transformed by Information, Chandler, A.D and Cortada, J.W. (eds.). Oxford: Oxford University Press, 107-136.

YOUNG A.A., 1928, Increasing returns and economic progress, Economic Journal, 38, 527-542. 


\section{Appendix}

\begin{tabular}{|c|c|}
\hline Variable & range/value \\
\hline $\begin{array}{l}\begin{array}{l}\text { Efficiency of internal and } \\
\text { external } \\
\text { activities }\left\{\theta_{\text {int }}, \theta_{\text {ext }}\right\}\end{array}\end{array}$ & $\begin{array}{l}\text { Scenario with external coordination } \\
\text { cost high }\{10,0.1\} \\
\text { Scenario with external coordination } \\
\text { cost same as internal }\{10,10\}\end{array}$ \\
\hline Outsourcing propensity os & $o s=0.2, o s=0.9$ \\
\hline Total number of services $F$ & $F=100$ \\
\hline Wage bill $w$ & $w=1$ \\
\hline Performance improvement $\tau$ & $N(0.01,0.0025)$ \\
\hline Supplier cost advantage $\gamma$ & $N(1,0.0625)$ \\
\hline Investment propensity $r$ & $N(0.02,0.0025)$ \\
\hline$\alpha_{\min }, \alpha_{\max }$ & $\alpha_{\min }=0.01 \alpha_{\max }=1$ \\
\hline$l_{p}$ & \\
\hline$l_{a}$ & $l_{a}=\frac{F}{F+v_{\mathrm{int}}+v_{\mathrm{ext}}}\left(1-l_{p}\right)$ \\
\hline$l_{c}$ & $l_{c}=\frac{v_{\mathrm{int}}+v_{\mathrm{ext}}}{F+v_{\mathrm{int}}+v_{\mathrm{ext}}}\left(1-l_{p}\right)$ \\
\hline$z$ & $z=\frac{F-N o s}{F}$ \\
\hline & $\begin{array}{l}\text { Nos }=\text { number of outsourced } \\
\text { services; } \sum_{h} \lambda_{i, h}=\text { Nos }\end{array}$ \\
\hline$l_{a, h}$ & $l_{a, h}=\frac{\lambda_{i, h}}{\lambda_{i, h}+v_{\mathrm{int}, h}+v_{\mathrm{ext}, h}}$ \\
\hline$l_{c, h}$ & $l_{c, h}=\frac{v_{\mathrm{int}, h}+v_{\mathrm{ext}, h}}{\lambda_{i, h}+v_{\mathrm{int}, h}+v_{\mathrm{ext}, h}}$ \\
\hline $\begin{array}{l}\text { Total consumer income } \\
\text { allocated to the firm in each } \\
\text { period } I s\end{array}$ & $I s=100$ \\
\hline Elasticity of demand $\eta$ & $\eta=1.5$ \\
\hline $\begin{array}{l}\text { Initial degree of decomposition } \\
\text { of the techno-organisational } \\
\text { design } n_{0}\end{array}$ & $n_{0}=5$ \\
\hline Average supplier mark-up & $\xi=.05$ \\
\hline$\mu_{i, 0}, i=1,2,3$ & $\mu_{1}=\mu_{2}=\mu_{3}=0 . \overline{3}$, at $t=0$ \\
\hline
\end{tabular}

Table A1: Parameter values used to calibrate the model 